\title{
Erratum to: Evolutionary trends of European bat lyssavirus type 2 including genetic characterization of Finnish strains of human and bat origin 24 years apart
}

Miia Jakava-Viljanen ${ }^{1}$ Tiina Nokireki ${ }^{1}$ Tarja Sironen ${ }^{2}$ Olli Vapalahti ${ }^{2,3}$. Liisa Sihvonen $^{1,3} \cdot$ Anita Huovilainen ${ }^{1}$

Published online: 4 June 2015

(C) Springer-Verlag Wien 2015

Erratum to: Arch Virol (2015) 160:1489-1498

DOI 10.1007/s00705-015-2424-0

Unfortunately, the given and family name of the complete author group was incorrect in the original publication. The correct version should read as:

Miia Jakava-Viljanen, Tiina Nokireki, Tarja Sironen, Olli Vapalahti, Liisa Sihvonen, Anita Huovilainen.

The online version of the original article can be found under doi:10.1007/s00705-015-2424-0.

Tiina Nokireki

tiina.nokireki@evira.fi

1 Finnish Food Safety Authority Evira, Mustialankatu 3, 00790 Helsinki, Finland

2 Department of Virology, University of Helsinki, POB 21, Helsinki, Finland

3 Department of Veterinary Biosciences, Faculty of Veterinary Medicine, University of Helsinki, POB 66,

FI-00014 Helsinki, Finland 